\title{
Educação inclusiva: uma garantia consagrada pelo estatuto da pessoa com deficiência
}

\author{
Marta Cristina Nunes Almeida ${ }^{1}$ \\ Rafael Santos Reis ${ }^{2}$ \\ Thainá Santos Santos
}

Resumo: A educação inclusiva é um direito fundamental com amparo na Constituição Brasileira de 1988 e em Convenções Internacionais. Com a entrada em vigência do Estatuto da Pessoa com Deficiência, o indivíduo que tem impedimento de longo prazo de natureza física, mental, intelectual ou sensorial passou a gozar de capacidade jurídica, tendo suas garantias previstas de forma expressa. Nessa senda, a lei 13.146, de 06 de julho de 2015, representa uma homenagem ao Princípio da Dignidade Humana e determina que o acesso à educação aconteça de forma plena e participativa. A defesa de tal garantia deve ser observada por instituições de ensino públicas e privadas, sob pena do cometimento de crime punível comreclusão em caso de desobediência, em consonância com entendimento do Supremo Tribunal Federal. É importante que o disposto na lei supracitada seja colocado em prática, para que seja possível a formação de uma sociedade justa e igualitária.

Palavras-chave: Educação. Pessoa com Deficiência. Inclusão.

Abstract: The inclusive education is a fundamental right than is protected in the 1988 Brazilian Constitution and international conventions. With the coming into force of the Statute of Persons with Disabilities, the individual who has cause long-term physical, mental, intellectual or sensory impairments came to enjoy legal capacity, and its guarantees provided for expressly. In this vein, the law 13146 of 06 July 2015, is a tribute to the principle of human dignity and determines that access to education happens in a full and participatory way.The defense of such guarantee shall be observed by public and private educational institutions, under penalty of committing a crime punishable by imprisonment in case of disobedience, in line with understanding the Supreme Court.It is important that the provisions of the above law is put into practice for the formation of a just and egalitarian society possible.

Keywords: Education. Deficiency Person.Inclusion.

\footnotetext{
${ }^{1}$ Professora do Curso de Direito da Universidade Estadual do Sudoeste da Bahia (UESB). Defensora Pública do Estado da Bahia, Especialista em Novos Direitos e Direitos Emergentes pela Universidade Estadual do Sudoeste da Bahia (2000), Graduada em Direito pela Universidade Católica do Salvador (1985). E-mail: marta.almeida@defensoria.ba.def.br.

2 Graduando em Direito pela Universidade Estadual do Sudoeste da Bahia (UESB). E-mail: rafaelsantosreis2@gmail.com.

${ }^{3}$ Graduanda em Direito pela Universidade Estadual do Sudoeste da Bahia (UESB). E-mail: thaina.ts@hotmail.com.
}

Página 19 Caderno de Ciências Sociais Aplicadas, Vitória da Conquista/BA, vol. 15, n 25, ano 15, p. 19-39, jan/jun 2018. 


\title{
Introdução
}

A educação possui um papel fundamental na construção de uma sociedade justa e igualitária. O direito à educação deve ter como objetivo desenvolver todas as potencialidades dos indivíduos para que possam exercer de forma integral a sua cidadania e ter acesso a todos os recursos da sociedade.

A discussão sobre a educação inclusiva engloba o papel do Poder Público e das instituições, bem como as contribuições da sociedade, sob uma perspectiva de acolher a diversidade humana, garantindo a todos a possibilidade de desfrutar dos seus direitos fundamentais.

Em apreço à isonomia substancial, é dever do Estado identificar as necessidades especiais dos indivíduos e oferecer respostas educativas adequadas a tais exigências. O princípio da igualdade de condições assegura que os deficientes devem ter igualdade de oportunidades no acesso e permanência à escola, vedado qualquer tipo de discriminação. A respeito dessa igualdade, SARLET (2009) leciona que:

\begin{abstract}
$\mathrm{Na}$ condição de direito subjetivo, o direito de igualdade opera como fundamento de posições individuais e mesmo coletivas que tem por objeto, na perspectiva negativa (defensiva), a proibição de tratamentos (encargos) em desacordo com as exigências da igualdade, ao passo que na perspectiva positiva ele opera como fundamento de direitos derivados a prestações, isto é, de igual acesso às prestações (bens, serviços, subvenções etc.), disponibilizados pelo Poder Público ou por entidades privadas na medida em que vinculadas ao princípio e direito de igualdade. Também a exigência de medidas que afastem desigualdades de fato e promovam a sua compensação, ou seja, de políticas de igualdade e mesmo políticas de ações afirmativas pode ser reconduzida à função positiva (prestacional) da igualdade, que implica um dever de atuação estatal, seja na esfera normativa, seja na esfera fática, de modo que é possível falar em uma imposição constitucional de uma igualdade de oportunidades.
\end{abstract}

Nesse sentido, é importante compreender que o Estatuto da Pessoa com Deficiência representa um marco social e jurídico no tratamento da pessoa com deficiência, trazendo um avanço significativo no processo de inclusão deste indivíduo nos espaços sociais, uma vez que esta legislação busca concretizar todos os direitos já assegurados constitucionalmente na tentativa de garantir uma vida digna eum ambiente social acessível a todos.

O objetivo deste estudo é investigar de que forma pode ocorrer a emancipação e a efetivação dos direitos garantidos às pessoas com deficiência, com ênfase na educação como um instrumento de mudança por meio da quebra de paradigmas, necessárias para a promoção da igualdade e da dignidade da pessoa humana.

Página 20 Caderno de Ciências Sociais Aplicadas, Vitória da Conquista/BA, vol. 15, n 25, ano 15, p. 19-39, jan/jun 2018. 


\section{Reflexões históricas: $O$ reconhecimento da pessoa com deficiência ao longo do tempo e a evolução legislativa}

Para compreender o processo de inclusão das pessoas com deficiência, é essencial percorrer a trajetória de luta e sobrevivência desse grupo populacional, analisando a evolução no tratamento dispensado a esses indivíduos ao longo da história.

Pode-se observar que a percepção social em relação aos indivíduos com deficiência permaneceu durante muito tempo inalterada, pois foram estigmatizados, marginalizados e execrados ao longo dos séculos.

Primeiramente, reportando-se à História Antiga e Medieval, os deficientes passaram por uma fase de eliminação sumária. Costumava-se justificar a deficiência de uma pessoa com causas sobrenaturais e preexistentes a seu nascimento, carregando, deste modo, uma imagem de imperfeição humana. Neste período, os bebês nascidos com deficiência eram sacrificados, abandonados ou escondidos por seus pais, e as pessoas que porventura adquirissem alguma deficiência ao longo de sua vida eram lançadas ao mar ou jogadas de precipícios.

Por volta do final do século IV até meados do século $\mathrm{V}$, a visão demonológica dos deficientes foi fortemente difundida, e eram vistos como seres dotados de poderes malignos. Com a publicação do livro"MalleusMaleficarum" que ficou conhecido como Martelo dos Bruxos na Alemanha, passou-se a acreditar que as deficiências e enfermidades eram geradas por bruxas com o intermédio do demônio.

Com o surgimento do Cristianismo, o nascimento de crianças com deficiência era encarado como um castigo ou erro de Deus, sendo apregoado que seria o indivíduo o culpado por sua condição. Contudo, as igrejas procuraram combater a prática do infanticídio e, deste modo, acolhiam as crianças que eram abandonadas bem como os adultos, havendo, portanto, uma aceitação por caridade. Os deficientes que sobreviviam e continuavam nas cidades ou eram escravizados ou eram tratados como aberrações e utilizados como atrações circenses.

Cumpre ressaltar que a ideia do assistencialismo já era difundida desde a era pré-cristã em outras sociedades, como, por exemplo, na Índia e na China, entretanto, coexistia a prática de eliminação das crianças deficientes.

No período da Inquisição, a Igreja Católica iniciou um movimento em que todos aqueles que estavam de encontro com os dogmas cristãos e aqueles que eram considerados "endemoniados" seriam submetidos a prisões e a várias outras punições severas, inclusive mortes na fogueira. Isso permitiu que

Página 21 Caderno de Ciências Sociais Aplicadas, Vitória da Conquista/BA, vol. 15, n 25, ano 15, p. 19-39, jan/jun 2018. 
ocorresse a morte de inúmeros deficientes, uma vez que eram vistos como instrumentos do demônio e sinais da ira divina.

Com o Renascimento, ainda se acreditava nas razões espirituais para a ocorrência das deficiências e enfermidades. Em contrapartida, com o processo de desenvolvimento das ciências, despertou-se um interesse pelo corpo e pela anatomia humana, passando a deficiência a ser compreendida como algo a ser tratado pela medicina, surgindo, a partir disso, os primeiros hospitais psiquiátricos.

No Brasil, as crianças com deficiência também eram abandonadas, e, no século XVIII, foram criadas as rodas dos expostos ou enjeitados, com a finalidade de que as instituições de caridade pudessem acolher as crianças que tinham sido desamparadas.

No século XVIII, com o advento da Revolução Francesa, começaram a ser propagadas novas ideologias que tinham por base o igualitarismo. Marco importante deste período histórico é a Declaração do Homem e do Cidadão, proclamada no ano de 1789. Tal documento teve como objetivo proteger os indivíduos contra os arbítrios dos que estavam no poder e elencar os direitos fundamentais garantidos a todos.

Com a Revolução Industrial, percebeu-se a importância de habilitar os deficientes para que estes também passassem a se tornar força de trabalho e incluiu-se a reabilitação daqueles que se tornavam deficientes por conta de acidentes decorrentes do labor.

No século XIX, houve uma especialização nos estudos e no tratamento de cada deficiência. No Brasil, foram instituídos o Imperial Instituto dos Meninos Cegos e o Imperial Instituto dos SurdosMudos.

Já no século XX houve um avanço substancial no reconhecimento dos direitos das pessoas com deficiência, bem como da sociedade em geral. Por conta das guerras, o tema ganhou bastante relevância devido à grande quantidade de pessoas que passaram a necessitar de cuidados especiais. No Brasil, foram criados centros especializados para o tratamento e reabilitação de crianças com deficiência e houve a aceitação de deficientes mentais em escolas públicas.

Nesse período foi criada a Organização Internacional do Trabalho, que se preocupou em oferecer melhorias para adequar o ambiente de trabalho às pessoas com deficiência.

Em 1948, com a Declaração Universal dos Direitos Humanos, foi assegurado de forma igualitária a todos os indivíduos um conjunto de direitos fundamentais inderrogáveis que tem como valor fundamental a dignidade da pessoa humana.

Página 22 Caderno de Ciências Sociais Aplicadas, Vitória da Conquista/BA, vol. 15, n 25, ano 15, p. 19-39, jan/jun 2018. 
Em 1958, foi realizada a Convenção no 111 sobre a Discriminação em Matéria de Emprego e Profissão, na qual os Estados-membros deveriam criar uma política nacional de ação afirmativa, a fim de promover a igualdade de oportunidades no mercado de trabalho.

Em 1967 foi feita a primeira menção sobre as pessoas com deficiência em uma Constituição brasileira. A Emenda $n^{\circ} 01$ estabeleceu que as pessoas com deficiência, introduzidas no diploma legal por meio da expressão “excepcionais", tivessem garantidos o seu direito à educação e, posteriormente, com a Emenda n 12 na mesma Constituição, assegurou a melhoria de sua condição social e econômica que se daria mediante o oferecimento de uma educação especial e gratuita, ressaltando, ainda, a proibição de discriminação.

A Declaração dos Direitos do Retardado Mental foi aprovada em 1971, garantindo aos deficientes os mesmos direitos de todos os seres humanos, repudiando qualquer forma de supressão de seus direitos.

No ano de 1975 foi aprovada a Declaração dos Direitos das Pessoas Deficientes, reafirmando que estas são titulares dos mesmos direitos fundamentais dos demais cidadãos. Para esta declaração, pessoa com deficiência é aquela "incapaz de assegurar porsi mesma, total ou parcialmente, as necessidades de uma vida individual ou social normal, em decorrência de uma deficiência, congênita ou não, em suas capacidades físicas ou mentais.” Em seguida, a referida Declaração afirma que:

As pessoas deficientes gozarão de todos os diretos estabelecidos a seguir nesta Declaração. Estes direitos serão garantidos a todas as pessoas deficientes sem nenhuma exceção e sem qualquer distinção ou discriminação com base em raça, cor, sexo, língua, religião, opiniões políticas ou outras, origem social ou nacional, estado de saúde, nascimento ou qualquer outra situação que diga respeito ao próprio deficiente ou a sua família.

$[\ldots]$

As pessoas deficientes têm os mesmos direitos civis e políticos que outros seres humanos

O ano de 1981 foi proclamado, pelas Nações Unidas, como o Ano Internacional das Pessoas Deficientes e teve como lema a "Participação plena e igualdade". A finalidade desta Proclamação foi promover um plano de ações que garantissem a igualdade nos direitos e deveres de participação das pessoas com deficiência na sociedade.

Em seguida, o período entre os anos de 1983 a 1992 foi declarado como a Década das Nações Unidas para as Pessoas com Deficiência pela ONU, com o objetivo de executar as ações pertencentes ao Programa de Ação Mundial relativo a Pessoas com Deficiência.

Página 23 Caderno de Ciências Sociais Aplicadas, Vitória da Conquista/BA, vol. 15, n 25, ano 15, p. 19-39, jan/jun 2018. 
Em 1983, a OIT editou a Convenção no 159 , que trata da reabilitação profissional das pessoas com deficiência, tendo por finalidade auxiliar esses indivíduos em sua reabilitação de modo que pudessem conseguir e manter um emprego digno.

Em 1988 foi promulgada a Constituição da República Federativa do Brasil que, seguindo os princípios da Declaração dos Direitos Humanos, assegurou os direitos fundamentais sem discriminação entre todos os indivíduos.

No ano de 1989 foi aprovada a lei no 7.853 da Política Nacional para a Integração da Pessoa Portadora de Deficiência, que sistematizou os direitos mínimos dos deficientes.

Em 1990 foi aprovada a "Declaração Mundial sobre Educação para Todos", que dispôs sobre as bases para uma educação inclusiva que permitisse o acesso de todas as pessoas aos conhecimentos básicos. Esta declaração deliberou sobre as necessidades essenciais de aprendizagem, com a finalidade de permitir que todos tenham acesso aos conhecimentos elementares que possam tornar suas vidas mais dignas, permitindo a construção de uma sociedade mais humana e justa. Ao tratar da universalização do acesso à educação e promoção da equidade, a declaração dispõe, in verbis, "As necessidades básicas de aprendizagem das pessoas portadoras de deficiências requerem atenção especial. É preciso tomar medidas que garantam a igualdade de acesso à educação aos portadores de todo e qualquer tipo de deficiência, como parte integrante do sistema educativo."

Em 1994 foi publicada a Declaração de Salamanca, sendo esta uma resolução da Organização das Nações Unidas. Este documento versa sobre os princípios e as políticas que estruturam a educação especial de acordo com o movimento de inclusão social. Deste modo, a Declaração pode lançar as bases de uma educação inclusiva que alcance todas as pessoas.

Em 1999, foi inserido no Decreto $n^{\circ} 3.298$, o compromisso de inserção das pessoas com deficiência no mercado de trabalho.

Ainda em 1999, a Organização dos Estados Americanos editou a Convenção Interamericana para a eliminação de todas as formas de discriminação contra as pessoas com deficiência. Esta Convenção obriga a todos os consignatários a adoção das medidas necessárias para eliminar a discriminação contra as pessoas com deficiência e proporcionar a sua plena integração na sociedade.

No ano de 2000, foi editada a lei no 10.098 que trouxe as bases para a promoção da acessibilidade às pessoas com deficiência ou com mobilidade reduzida.

A Convenção dos Direitos da Pessoa com Deficiência, datada de 2006, foi um instrumento internacional de direitos humanos das Nações Unidas que reconheceu os direitos das pessoas com

Página 24 Caderno de Ciências Sociais Aplicadas, Vitória da Conquista/BA, vol. 15, n 25, ano 15, p. 19-39, jan/jun 2018. 
deficiência, proibindo a discriminação em qualquer área e responsabilizando toda a sociedade a adotar medidas que assegurem a efetivação e o pleno exercício dos seus direitos fundamentais.

Por fim, no ano de 2015 foi editada a lei no 13.146, instituindo o "Estatuto da Pessoa com Deficiência", que, de acordo com seu artigo $1^{\circ}$, destina-se "a assegurar e a promover, em condições de igualdade, o exercício dos direitos e das liberdades fundamentais por pessoa com deficiência, visando à sua inclusão social e cidadania." Esta lei vem para concretizar os direitos constantes na Constituição de 1988, tendo em vista que a igualdade deve ser exercida de forma substancial.

Conforme preceitua GALIANO (2015)

Pensamos que a nova Lei veio em boa hora, ao conferir um tratamento mais digno às pessoas com deficiência. Verdadeira reconstrução valorativa na tradicional tessitura do sistema jurídico brasileiro da incapacidade civil. Mas o grande desafio é a mudança de mentalidade, na perspectiva de respeito à dimensão existencial do outro. Mais do que leis, precisamos mudar mentes e corações.

Dessa forma, é importante entender que o Estatuto da Pessoa com Deficiência é uma homenagem aos princípios da igualdade e da dignidade da pessoa humana, garantindo uma conquista social, consentindo em um sistema normativo inclusivo e com regras expressas acerca da implantação de um sistema educacional condizente com o verdadeiro significado da dignidade humana contemporânea.

\section{Educação inclusiva: amparo constitucional e internacional}

No que diz respeito ao aspecto educacional, faz-se necessário compreender que a pessoa com deficiência não fazia parte do ambiente escolar, uma vez que era tido como fora dos padrões de "normalidade" e, portanto, apartado dos espaços de convivência.

A Constituição do Brasilde 1988 estabelece a educação como um direito fundamental social que deve integrar o conteúdo do mínimo existencial, e que o Estado tem o dever de assegurar a sua prestação e a universalização. Nessa perspectiva, cumpre observar os artigos 205 a 208 da Carta Magna de 1988 que procuram delinear os aspectos essenciais desse direito. No que se refere à garantia de acesso de todas as pessoas, inclusive daquelas que possuem algum tipo de deficiência, dispõe:

Página 25 Caderno de Ciências Sociais Aplicadas, Vitória da Conquista/BA, vol. 15, n 25, ano 15, p. 19-39, jan/jun 2018. 
Art. 205. A educação, direito de todos e dever do Estado e da família, será promovida e incentivada com a colaboração da sociedade, visando ao pleno desenvolvimento da pessoa, seu preparo para o exercício da cidadania e sua qualificação para o trabalho. Art. 206. O ensino será ministrado com base nos seguintes princípios:

I - igualdade de condições para o acesso e permanência na escola;

Posteriormente, preleciona o artigo 208, inciso III do supracitado diploma legal:

Art. 208. O dever do Estado com a educação será efetivado mediante a garantia de: $[\ldots]$

III - atendimento educacional especializado aos portadores de deficiência, preferencialmente na rede regular de ensino;

Assim sendo, foi garantida constitucionalmente a educação especial às pessoas com deficiência em igualdade de oportunidades das demais pessoas.

Partindo da análise de que o direito à educação é uma garantia fundamental, é importante para um melhor entendimento do tema a percepção de que os amparos legais do ensino inclusivo, que também deram suporte para a elaboração da lei no 13.146, de 06 de Julho de 2015, se sedimentaram em Conferências Internacionais.

Posto isso, as Convenções que ganharam notoriedade diante do seu aprofundamento teórico sobre os direitos da pessoa com deficiência foram a Conferência Mundial em Educação Especial organizada pelo governo da Espanha em cooperação com a UNESCO, realizada em Salamanca entre 07 e 10 de junho de 1994, e a Convenção Internacional dos Direitos das Pessoas com Deficiência de Nova York. Ambas trouxeram entendimentos revolucionários a respeito da educação inclusiva e sobre as garantias plurais para o deficiente, reconhecendo este sob a égide do princípio da dignidade da pessoa humana.

\section{Convenção de Salamanca: marco histórico para a educação inclusiva}

Primeiramente, é necessário compreender que a Declaração de Salamanca é considerado um dos principais documentos mundiais que visam à inclusão social. A convenção coloca a educação como protagonista de desenvolvimento cultural, econômico e político contribuindo diretamente na formação de cidadãos críticos, conscientes e politizados, não admitindo que o deficiente seja excluído desse processo de ensino. Vale salientar que o referido encontro internacional se preocupava

Página 26 Caderno de Ciências Sociais Aplicadas, Vitória da Conquista/BA, vol. 15, nº 25, ano 15, p. 19-39, jan/jun 2018. 
primordialmente com a democratização do ensino a fim de que se efetivasse a inclusão dos alunos com deficiência. A conferência de Salamanca afirma:

Proporcionou uma oportunidade única de colocação da educação especial dentro da estrutura de "educação para todos" firmada em 1990 (...) Ela promoveu uma plataforma que afirma o princípio e a discussão da prática de garantia de inclusão das crianças com necessidades educacionais especiais nestas iniciativas e a tomada de seus lugares de direito numa sociedade de aprendizagem. ${ }^{4}$

No que se refere ao conceito de necessidades educacionais especiais, a Declaração afirma que:

Durante os últimos 15 ou 20 anos, tem se tornado claro que o conceito de necessidades educacionais especiais teve que ser ampliado para incluir todas as crianças que não estejam conseguindo se beneficiar com a escola, seja por que motivo for. ${ }^{5}$

Este entendimento mais amplo do conceito de necessidades especiais apresenta uma consonância com a lei $\mathrm{n}^{\mathrm{o}}$ 13.146, de 06 de Julho de 2015 que também traz em seu texto uma generalidade do conceito de deficiência quando aduz que:

Art. $2^{\circ}$ Considera-se pessoa com deficiência aquela que tem impedimento de longo prazo de natureza física, mental, intelectual ou sensorial, o qual, em interação com uma ou mais barreiras, pode obstruir sua participação plena e efetiva na sociedade em igualdade de condições com as demais pessoas.

Desse modo, percebe-se nos referenciais estabelecidos pela Convenção a imensa tentativa de assegurar o ensino para aqueles que tivessem qualquer dificuldade no aprendizado, não trazendo delimitações preconceituosas e rotulárias. Estas realidades que foram recepcionadas pelo Estatuto da Pessoa com Deficiência homenageiam o princípio Constitucional da isonomia.

A respeito de tal princípio, é oportuno demonstrar as construções doutrinárias para que se possa interpretar a expressão da Carta Magna brasileira de que todos serão iguais perante a lei. Nesse sentido, vejamos algumas considerações:

Ruy Barbosa, orientando-se na lição Aristotélica, anunciou que "a regra da igualdade não consiste senão em tratar desigualmente os desiguais na medida em que se desigualam. Nesta desigualdade social,

${ }^{4}$ UNESCO/Ministry of Education and Science -Spain.
${ }^{5}$ UNESCO/Ministry of Education and Science-Spain.

Página 27 Caderno de Ciências Sociais Aplicadas, Vitória da Conquista/BA, vol. 15, n 25, ano 15, p. 19-39, jan/jun 2018. 
proporcional e desigualdade natural, é que se acha a verdadeira lei da igualdade. Os mais são desvarios da inveja, do orgulho ou da loucura. Tratar com desigualdade os iguais, ou os desiguais com igualdade, seria desigualdade flagrante, e não igualdade real. Os apetites humanos conceberam inverter a norma universal da criação, pretendendo, não dar a cada um, na razão do que vale, mas atribuir os mesmos a todos, como se todos se equivalessem" (BULOS, 2009, p. 420.)

Estabelecendo como ponto fulcral o pensamento de Aristóteles, a Convenção de Salamanca reconhece a essencialidade do ensino inclusivo, para que jovens portadores de deficiência consigam se desenvolver socialmente, sendo tratados de forma igualitária. A Declaração aduz em suas páginas que, ipsis litteris:

O princípio fundamental da escola inclusiva é o de que todas as crianças deveriam aprender juntas, independentemente de quaisquer dificuldades ou diferenças que possam ter. As escolas inclusivas devem reconhecer e responder às diversas necessidades de seus alunos, acomodando tanto estilos como ritmos diferentes de aprendizagem e assegurando uma educação de qualidade a todos através de currículo apropriado, modificação organizacional, estratégias de ensino, uso de recursos e parcerias com a comunidade (...). Dentro das escolas inclusivas, as crianças com necessidades educacionais especiais deveriam receber qualquer apoio extra que possam precisar, para que se lhes assegure uma educação efetiva (...).

É visível a preocupação que a Convenção apresenta com a inclusão dos alunos com deficiência, orientando que os mesmos sejam inseridos na escola regular, cobrando uma atuação firme dos educadores na difusão do entendimento de que a diversidade é inerente à vida humana. Dessa forma, a própria Declaração esclarece que:

A inclusão e participação são essenciais à dignidade humana e ao gozo e exercício dos direitos humanos. No campo da educação, tal se reflete no desenvolvimento de estratégias que procuram proporcionar uma equalização genuína de oportunidades. A experiência em muitos países demonstra que a integração das crianças e jovens com necessidades educacionais especiais é mais eficazmente alcançada em escolas inclusivas que servem a todas as crianças de uma comunidade.

Destarte, é incontroversa a importância que a Convenção de Salamanca teve na consagração da educação inclusiva, de modo que as suas influências presentes no Estatuto da Pessoa com Deficiência demonstram com clareza a comunicabilidade da produção legislativa brasileira com os entendimentos

Página 28 Caderno de Ciências Sociais Aplicadas, Vitória da Conquista/BA, vol. 15, nº 25, ano 15, p. 19-39, jan/jun 2018. 
internacionais, que já são pacíficos no reconhecimento da essencialidade da inserção do deficiente no ambiente escolar. Nessa mesma linha se posiciona o pesquisador da temática, quando assevera:

Ao refletir sobre a abrangência do sentido e do significado do processo de Educação inclusiva, estamos considerando a diversidade de aprendizes e seu direito à equidade. Trata-se de equiparar oportunidades, garantindo-se a todos - inclusive às pessoas em situação de deficiência e aos de altas habilidades/superdotados, o direito de aprender a aprender, aprender a fazer, aprender a ser e aprender a conviver. (CARVALHO, 2005).

Portanto, fica evidente a importância da educação inclusiva no processo de aprendizagem, principalmente no que se refere à formação de um meio escolar cada vez mais plural, justo e igualitário.

\section{Convenção internacional de Nova York: a voz da pessoa com deficiência}

A Convenção Internacional sobre os Direitos da Pessoa com Deficiência é marcada por uma participação atuante da sociedade civil mundial. Diversos seguimentos sociais que estudam a temática tiveram a oportunidade de contribuir na elaboração do documento oficial da Convenção. Essa postura democrática é louvável, pois estabeleceu um diálogo direto com o deficiente, e, por consequência, os anseios destes puderam ser considerados na elaboração formal do Documento.

Vale salientar que os desígnios da Convenção de Nova York são o de promover, proteger e assegurar o exercício pleno e justo de todos os direitos humanos e liberdades fundamentais para todas as pessoas com deficiência, abrolhando o respeito pela sua dignidade inerente.

A base principiológica do documento comporta os princípios da autonomia individual, da não discriminação, da igualdade de oportunidades, do respeito à diferença, da acessibilidade, da participação e inclusão das pessoas com deficiência na sociedade. Dessa forma, é possível vislumbrar a relação da Convenção com a Declaração Universal dos Direitos Humanos, aprovada em 1948, sendo notória a preocupação com os direitos e garantias fundamentais do homem.

A revolução trazida por essa Convenção é gigantesca, pois rompe com resquícios históricos de que o portador de deficiência deveria ser apartado dos ambientes sociais e traz uma promessa emancipatória, no sentido de garantir para esses atores sociais a possibilidade de viver de forma independente e participar inteiramente de todos os aspectos da vida.

Página 29 Caderno de Ciências Sociais Aplicadas, Vitória da Conquista/BA, vol. 15, n 25, ano 15, p. 19-39, jan/jun 2018. 


\section{Cadernos de Ciências SOCIAIS APLICADAS}

A orientação trazida no documento da Convenção é de que os países deverão estabelecer propostas para assegurar às pessoas com deficiência o acesso, em igualdade de oportunidadescom as demais pessoas, ao meio físico, ao transporte, à informação e à comunicação, inclusive aos sistemas e tecnologias da informação, dentre outros serviços e instalações abertos ao público ou de uso público, tanto na zona urbana como na rural.

A Convenção Internacional sobre os Direitos das Pessoas com Deficiência e seu Protocolo Facultativo, assinados em Nova York, em 30 de Março de 2007, foram recepcionados com enorme relevância no âmbito jurídico brasileiro, de modo que receberam assento constitucional através do decreto no 6.949, de 25 de Agosto de 2009. O Decreto aduz que:

Art. $1^{\circ}$ A Convenção sobre os Direitos das Pessoas com Deficiência e seu Protocolo Facultativo, apensos por cópia ao presente Decreto, serão executados e cumpridos tão inteiramente como neles se contém.

$[\ldots]$

e) Reconhecendo que a deficiência é um conceito em evolução e que a deficiência resulta da interação entre pessoas com deficiência e as barreiras devidas às atitudes e ao ambiente que impedem a plena e efetiva participação dessas pessoas na sociedade em igualdade de oportunidades com as demais pessoas,

$[\ldots]$

g) Ressaltando a importância de trazer questões relativas à deficiência ao centro das preocupações da sociedade como parte integrante das estratégias relevantes de desenvolvimento sustentável, [...]

m) Reconhecendo as valiosas contribuições existentes e potenciais das pessoas com deficiência ao bem-estar comum e à diversidade de suas comunidades, e que a promoção do pleno exercício, pelas pessoas com deficiência, de seus direitos humanos e liberdades fundamentais e de sua plena participação na sociedade resultará no fortalecimento de seu senso de pertencimento à sociedade e no significativo avanço do desenvolvimento humano, social e econômico da sociedade, bem como na erradicação da pobreza.

Nesse contexto, a Constituição Cidadã de 1988 honrou seus princípios fundamentais quando ratificou a Convenção Internacional sobre os Direitos da Pessoa com Deficiência. Ademais, o próprio decreto traz expressamente em seu artigo terceiro os princípios gerais da convenção, estando em conformidade com entendimentos doutrinários da importância de valorar esses norteadores jurídicos:

\section{PRINCÍPIOS GERAIS}

a) $\mathrm{O}$ respeito pela dignidade inerente, a autonomia individual, inclusive a liberdade de fazer as próprias escolhas, e a independência das pessoas;

b) A não discriminação;

c) A plena e efetiva participação e inclusão na sociedade;

Página 30 Caderno de Ciências Sociais Aplicadas, Vitória da Conquista/BA, vol. 15, nº 25, ano 15, p. 19-39, jan/jun 2018. 
d) $\mathrm{O}$ respeito pela diferença e pela aceitação das pessoas com deficiência como parte da diversidade humana e da humanidade;

e) A igualdade de oportunidades;

f) A acessibilidade;

g) A igualdade entre o homem e a mulher;

h) O respeito pelo desenvolvimento das capacidades das crianças com deficiência e pelo direito das crianças com deficiência de preservar sua identidade.

A doutrina defende a necessidade da valorização dos princípios. Ronald Dworkin (2010), renomado jurista e filósofo norte-americano, trata da força normativa que existe nos princípios e regras.

Não apenas as regras são dotadas de força normativa, mas, também, os princípios; estes não existem simplesmente para colorir folhas em branco de papel ou para vender livros, existem para dar vida ao Direito. Porque um Direito que não se preocupa com princípios tais quais o da Justiça, é um Direito morto e não tem razão de ser. ${ }^{6}$

É inegável a contribuição que a Convenção Internacional sobre os Direitos da Pessoa com Deficiência traz para o Direito brasileiro, principalmente na elaboração do Estatuto da Pessoa com Deficiência de 2015, pois os princípios supracitados estão presentes tanto expressa ou implicitamente na lei $n^{\circ} 13.146$, tendo relevância crucial também na garantida da educação inclusiva.

\section{O ensino inclusivo e o estatuto da pessoa com deficiência: garantias expressas}

A educação é fundamental para que o homem exerça o seu papel de cidadão em uma sociedade cada vez mais plural, uma vez que é através dela que os atores sociais alcançarão o conhecimento e se tornarão críticos.

Como outrora abordado, o ensino compõe o rol de direitos fundamentais e não seria justo que tal garantia não fosse assegurada para a pessoa com deficiência. GIOVANA ZANINELLI e EDUARDO CAMBI $(2015)^{7}$ lecionam que:

Educação é um direito em si mesmo, mas também um meio indispensável para o acesso a outros direitos, e ganha maior importância quando direcionada ao pleno desenvolvimento humano e às suas potencialidades, em especial quando valoriza o respeito aos grupos socialmente excluídos. Valores, atitudes e comportamentos éticos,

\footnotetext{
${ }^{6}$ DWORKIN, Ronald. Levando os direitos a sério - 3 ed. - São Paulo: Editora WMF Martins Fontes, 2010.

7 CAMBI, Eduardo; ZANINELLI, Giovana. Direito fundamental à educação, exclusão social e cidadania. In: Doutrinas essenciais de Direito Constitucional. Vol. 9/2015, p. 721-748, ago./2015.
}

Página 31 Caderno de Ciências Sociais Aplicadas, Vitória da Conquista/BA, vol. 15, n 25, ano 15, p. 19-39, jan/jun 2018. 
além da defesa socioambiental e da justiça social, devem fazer parte das diretrizes educacionais e colaborarem para a construção de novos conhecimentos.

A Organização das Nações Unidas para a Educação, a Ciência e a Cultura (UNESCO), através de relatórios internacionais estabeleceu que a educação funda-se em quatro pilares:

(I) aprender a conhecer ("aprender a aprender, para beneficiar-se das oportunidades oferecidas pela educação ao longo da vida"), (II) aprender a fazer ("a competência que permita a pessoa apta a enfrentar numerosas situações e a trabalhar em equipe"), (III) aprender a conviver ("respeito pelos valores do pluralismo, da compreensão mútua e da paz") e (IV) aprender a ser ("a educação deve levar em consideração todas as potencialidades de cada indivíduo") 8 .

Os pilares estabelecidos estão de acordo com os fundamentos da educação inclusiva, visto que valoriza as diferenças e entende que a pessoa com deficiência deve participar do cotidiano da escola regular, sendo inserido por meio de uma pedagogia que forneça possibilidades específicas para o aprendizado. Nesse contexto:

Todas as pessoas têm o direito fundamental à Educação e que a educação para todos representa um consenso mundial de uma visão muito mais abrangente de educação básica, assim como representa um renovado compromisso para assegurar que as necessidades básicas de aprendizagem de todas as crianças, jovem ou adulta serão encontradas, efetivamente, em todos os países. (Haddad, Prefácio, 1990)

Dentro dessa realidade, é importante perceber que o Estatuto da Pessoa com Deficiência é uma homenagem ao princípio da dignidade da pessoa humana e está de acordo com o que recomenda a educação inclusiva. Assim sendo, a lei 13.146/2015 garante uma conquista social para a pessoa com deficiência - aquela que tem impedimento de longo prazo, de natureza física, mental, intelectual ou sensorial, nos termos do art. $2^{\circ}$ da referida lei, consentindo um sistema normativo inclusivo.

O Estatuto da Pessoa com Deficiência, nos termos do parágrafo único do seu artigo $1^{\circ}$, tem como base a Convenção sobre os Direitos das Pessoas com Deficiência e seu Protocolo Facultativo, ratificados pelo Congresso Nacional por meio do Decreto Legislativo n 186, de 09 de julho de 2008, em concordância com o procedimento previsto no $\int 3^{\circ}$ do art. $5^{\circ}$ da Constituição da República Federativa do Brasil. Tal dispositivo legal representa uma revolução no que diz respeito à capacidade

\footnotetext{
${ }^{8}$ UNESCO. Educação: um tesouro a descobrir. Relatório para a UNESCO daComissão Internacional sobre a educação para o século XXI. Trad. GuilhermeJoão de Freitas Teixeira. Brasília, 2010. Disponível em: $<$ http://unesdoc.unesco.org/images/0010/001095/109590por.pdf >.Acesso em: 03.09. 2016.
}

Página 32 Caderno de Ciências Sociais Aplicadas, Vitória da Conquista/BA, vol. 15, nº 25, ano 15, p. 19-39, jan/jun 2018. 
das pessoas naturais, quando aduz que, em regra, a pessoa com deficiência não é mais considerado civilmente incapaz. A lei dispõe sobre o assunto da seguinte maneira:

Art. $6^{\circ}$. A deficiência não afeta a plena capacidade civil da pessoa, inclusive para:

I - casar-se e constituir união estável;

II - exercer direitos sexuais e reprodutivos;

III - exercer o direito de decidir sobre o número de filhos e de ter acesso a informações adequadas sobre reprodução e planejamento familiar;

IV - conservar sua fertilidade, sendo vedada a esterilização compulsória;

$\mathrm{V}$ - exercer o direito à família e à convivência familiar e comunitária; e

VI - exercer o direito à guarda, à tutela, à curatela e à adoção, como adotante ou adotando, em igualdade de oportunidades com as demais pessoas.

$[\ldots]$

Art. $84^{\circ}$. A pessoa com deficiência tem assegurado o direito ao exercício de sua capacidade legal em igualdade de condições com as demais pessoas.

É de bom tom reconhecer que um dos principais objetivos do Estatuto da Pessoa com Deficiência é o de homenagear o princípio norteador do direito brasileiro, que é o princípio da dignidade da pessoa humana. É crucial o entendimento de que o texto normativo acarretou grandes consequências nos diversos ramos da ciência jurídica, haja vista que o diálogo com as diretrizes principiológicas reflete em toda a legislação posta. Estudiosos do tema asseveram que:

Em verdade, o que o Estatuto pretendeu foi homenagear o princípio da dignidade da pessoa humana, fazer com que a pessoa com deficiência deixasse de ser "rotulada" como incapaz, para ser considerada - em uma perspectiva constitucional isonômica dotada de plena capacidade legal, ainda que haja a necessidade de adoção de institutos assistenciais específicos (STOLZE, 2015).

O princípio da dignidade da pessoa humana, previsto no artigo $1^{\circ}$, inciso III, da Constituição da República de 1988, compreendido como núcleo essencial da República Federativa do Brasil traduz-se no reconhecimento do valor do indivíduo como limite e fundamento da organização política da sociedade. Constitui o fundamento de validade que harmoniza e inspira todo o ordenamento constitucional vigente, informando a base do ordenamento republicano e democrático. (CANOTILHO, 1998, p. 219)

"Temos por dignidade da pessoa humana a qualidade intrínseca e distintiva reconhecida em cada ser humano que o faz merecedor do mesmo respeito e consideração por parte do Estado e da comunidade, implicando, neste sentido, um complexo de direitos e deveres fundamentais que assegurem a pessoa tanto contra todo e qualquer ato de cunho degradante e desumano, como venham a lhe garantir as condições existenciais mínimas para uma vida saudável, além de propiciar e promover sua participação ativa e corresponsável nos destinos da própria existência e da vida em comunhão com os demais seres humanos mediante o devido respeito aos demais seres que integram a rede da vida." (SARLET, 2011, p. 73).

Página 33 Caderno de Ciências Sociais Aplicadas, Vitória da Conquista/BA, vol. 15, n 25, ano 15, p. 19-39, jan/jun 2018. 
Dentro desse contexto de proteção integral aos direitos fundamentais, um ponto de extrema relevância do Estatuto é a existência de artigos exclusivos dedicados à regulamentação do direito à educação, representando um avanço considerável na defesa da essencialidade do ensino inclusivo, coadunando com o preconizado pela Convenção de Salamanca, bem como pela Convenção Internacional sobre os Direitos da Pessoa com Deficiência. O Capítulo IV da lei 13.146/2015 explica que:

Art. $27^{\circ}$. A educação constitui direito da pessoa com deficiência, assegurados sistema educacional inclusivo em todos os níveis e aprendizado ao longo de toda a vida, de forma a alcançar o máximo desenvolvimento possível de seus talentos e habilidades físicas, sensoriais, intelectuais e sociais, segundo suas características, interesses e necessidades de aprendizagem.

Parágrafo único. É dever do Estado, da família, da comunidade escolar e da sociedade assegurar educação de qualidade à pessoa com deficiência, colocando-a a salvo de toda forma de violência, negligência e discriminação.

Art. $28^{\circ}$. Incumbe ao poder público assegurar, criar, desenvolver, implementar, incentivar, acompanhar e avaliar:

I - sistema educacional inclusivo em todos os níveis e modalidades, bem como o aprendizado ao longo de toda a vida;

II - aprimoramento dos sistemas educacionais, visando a garantir condições de acesso, permanência, participação e aprendizagem, por meio da oferta de serviços e de recursos de acessibilidade que eliminem as barreiras e promovam a inclusão plena;

III - projeto pedagógico que institucionalize o atendimento educacional especializado, assim como os demais serviços e adaptações razoáveis, para atender às características dos estudantes com deficiência e garantir o seu pleno acesso ao currículo em condições de igualdade, promovendo a conquista e o exercício de sua autonomia;

IV - oferta de educação bilíngue, em Libras como primeira língua e na modalidade escrita da língua portuguesa como segunda língua, em escolas e classes bilíngues e em escolas inclusivas;

V - adoção de medidas individualizadas e coletivas em ambientes que maximizem o desenvolvimento acadêmico e social dos estudantes com deficiência, favorecendo o acesso, a permanência, a participação e a aprendizagem em instituições de ensino;

VI - pesquisas voltadas para o desenvolvimento de novos métodos e técnicas pedagógicas, de materiais didáticos, de equipamentos e de recursos de tecnologia assistiva;

VII - planejamento de estudo de caso, de elaboração de plano de atendimento educacional especializado, de organização de recursos e serviços de acessibilidade e de disponibilização e usabilidade pedagógica de recursos de tecnologia assistiva;

VIII - participação dos estudantes com deficiência e de suas famílias nas diversas instâncias de atuação da comunidade escolar

IX - adoção de medidas de apoio que favoreçam o desenvolvimento dos aspectos linguísticos, culturais, vocacionais e profissionais, levando-se em conta o talento, a criatividade, as habilidades e os interesses do estudante com deficiência;

$\mathrm{X}$ - adoção de práticas pedagógicas inclusivas pelos programas de formação inicial e continuada de professores e oferta de formação continuada para o atendimento educacional especializado;

Página 34 Caderno de Ciências Sociais Aplicadas, Vitória da Conquista/BA, vol. 15, nº 25, ano 15, p. 19-39, jan/jun 2018. 
XI - formação e disponibilização de professores para o atendimento educacional especializado, de tradutores e intérpretes da Libras, de guias intérpretes e de profissionais de apoio;

XII - oferta de ensino da Libras, do Sistema Braille e de uso de recursos de tecnologia assistiva, de forma a ampliar habilidades funcionais dos estudantes, promovendo sua autonomia e participação;

XIII - acesso à educação superior e à educação profissional e tecnológica em igualdade de oportunidades e condições com as demais pessoas;

XIV - inclusão em conteúdos curriculares, em cursos de nível superior e de educação profissional técnica e tecnológica, de temas relacionados à pessoa com deficiência nos respectivos campos de conhecimento;

$\mathrm{XV}$ - acesso da pessoa com deficiência, em igualdade de condições, a jogos e a atividades recreativas, esportivas e de lazer, no sistema escolar;

XVI - acessibilidade para todos os estudantes, trabalhadores da educação e demais integrantes da comunidade escolar às edificações, aos ambientes e às atividades concernentes a todas as modalidades, etapas e níveis de ensino;

XVII - oferta de profissionais de apoio escolar;

XVIII - articulação Inter -setorial na implementação de políticas públicas.

$\int 1^{\circ}$ Às instituições privadas, de qualquer nível e modalidade de ensino, aplica-se obrigatoriamente o disposto nos incisos I, II, III, V, VII, VIII, IX, X, XI, XII, XIII, XIV, XV, XVI, XVII e XVIII do caput deste artigo, sendo vedada a cobrança de valores adicionais de qualquer natureza em suas mensalidades, anuidades e matrículas no cumprimento dessas determinações.

$\int 2^{\circ} \mathrm{Na}$ disponibilização de tradutores e intérpretes da Libras a que se refere o inciso XI do caput deste artigo, deve-se observar o seguinte:

I - os tradutores e intérpretes da Libras atuantes na educação básica devem, no mínimo, possuir ensino médio completo e certificado de proficiência na Libras; (Vigência)

II - os tradutores e intérpretes da Libras, quando direcionados à tarefa de interpretar nas salas de aula dos cursos de graduação e pós-graduação, devem possuir nível superior, com habilitação, prioritariamente, em Tradução e Interpretação em Libras.

A interpretação mais acertada dos artigos supracitados é que o direito à educação não pode ser ceifado da pessoa com deficiência, pois esse indivíduo dispõe da garantia de ter acesso a um ensino digno e coerente com suas necessidades especiais.

De acordo com o que preconizam as determinações do capítulo referente ao ensino inclusivo no Estatuto, cabe ao Estado, bem como às instituições privadas, desenvolverem possibilidades e mecanismos para que o deficiente consiga absorver os conteúdos por intermédio de técnicas pedagógicas inclusivas.

Cumpre ressaltar que não poderá ser cobrada nenhuma taxa adicional ao portador de deficiência para que o mesmo possa gozar do ensino inclusivo. A vedação legal do Estatuto rompe com práticas reiteradas de algumas escolas privadas que costumavam exigir uma mensalidade maior para o sujeito

Página 35 Caderno de Ciências Sociais Aplicadas, Vitória da Conquista/BA, vol. 15, n² 25, ano 15, p. 19-39, jan/jun 2018. 
com necessidades especiais e por vezes rejeitavam em efetivar a matrícula dos mesmos, em uma latente ofensa ao princípio constitucional da isonomia.

A consagração da educação inclusiva oriunda da lei 13.146/2015, é uma grande conquista na luta pela igualdade, tendo a lei apresentado meios sancionatórios para inibir posturas que confrontam a garantia deste direito. O Estatuto preconiza que:

Art. 98. A Lei no 7.853, de 24 de outubro de 1989, passa a vigorar com as seguintes alterações:

"Art. $3^{\circ}$ As medidas judiciais destinadas à proteção de interesses coletivos, difusos, individuais homogêneos e individuais indisponíveis da pessoa com deficiência poderão ser propostas pelo Ministério Público, pela Defensoria Pública, pela União, pelos Estados, pelos Municípios, pelo Distrito Federal, por associação constituída há mais de 1 (um) ano, nos termos da lei civil, por autarquia, por empresa pública e por fundação ou sociedade de economia mista que inclua, entre suas finalidades institucionais, a proteção dos interesses e a promoção de direitos da pessoa com deficiência.

“Art. $8^{\circ}$ Constitui crime punível com reclusão de 2 (dois) a 5 (cinco) anos e multa: I - recusar, cobrar valores adicionais, suspender, procrastinar, cancelar ou fazer cessar inscrição de aluno em estabelecimento de ensino de qualquer curso ou grau, público ou privado, em razão de sua deficiência.

É importante salientar que a constitucionalidade do $\int 1^{\circ}$ do Artigo 28 do Estatuto da Pessoa com Deficiência, que versa sobre as obrigações das instituições privadas para com o ensino inclusivo, já recebeu o amparo do Supremo Tribunal Federal em julgamento da Ação Direta de Inconstitucionalidade-ADI n 5357, que pretendia a suspensão da eficácia dos dispositivos atacados até o julgamento do mérito da ação, arguindo a ofensa do dispositivo ao texto da Carta Magna de 1988. A ação foi ajuizada pela Confederação Nacional dos Estabelecimentos de Ensino (Confenen) que argumentava dizendo que, verbis, "As exigências realizadas tornarão os valores necessários ao custeio na educação privada proibitivos, e dessa forma, comprometendo a existência da escola privada". Felizmente o requerimento não logrou êxito no plenário do Supremo, que demostrou, por meio dos votos dos Ministros, um verdadeiro reconhecimento do Princípio da Dignidade da Pessoa Humana. O relator do processo, o Ministro Edson Fachin, indeferiu a liminar e relatou de forma desfavorável à petição inicial. Em plenário foi construída a seguinte decisão para a $\operatorname{ADIn}^{\circ}$ 5357:

O Tribunal, por unanimidade, deliberou converter o julgamento do referendo da cautelar em julgamento de mérito, julgando, por maioria, improcedente a ação direta, vencido, no ponto, o Ministro Marco Aurélio, que a julgava parcialmente procedente; tudo nos termos do voto do Relator.

Página 36 Caderno de Ciências Sociais Aplicadas, Vitória da Conquista/BA, vol. 15, n 25, ano 15, p. 19-39, jan/jun 2018. 
O Supremo Tribunal Federal, na condição de guardião constitucional, não poderia ter outra conduta, pois, modo contrário, estaria ferindo o espírito do constituinte originário. A decisão corrobora com o disposto na Convenção de Salamanca e fortalece a proposta do Estatuto da Pessoa com Deficiência no sentido de ser um texto legal que luta pelo combate às discriminações da pessoa com deficiência, reconhecendo a educação inclusiva como um direito fundamental do ser humano.

Acentua-se ainda o fato de que por ser a educação um direito humano reconhecido pela Declaração Universal dos Direitos Humanos, em face de sua proteção especial, tem o Estado o dever de promovê-lo de forma satisfativa e igualitária a todos os indivíduos, sob pena de responder internacionalmente pelos seus atos ou omissões.

\section{Considerações finais}

Pode-se perceber que ao longo da história a pessoa com deficiência sempre foi apartada dos ambientes sociais por conta da sua condição de diferença dos padrões de normalidade estabelecidos pela consciência social. Foi mediante um longo processo de luta e resistência que estes indivíduos puderam se firmar como sujeito de direitos e garantir a sua condição de igualdade.

A educação tem papel fundamental na busca pela concretização dos demais direitos, uma vez que é por meio dela que o indivíduo pode desenvolver a sua atuação no mundo. Na perspectiva de uma educação inclusiva, a efetivação do direito não se dá apenas com a presença do deficiente em sala de aula. Portanto, é importante ressaltar que as instituições de ensino devem estar preparadas para receber esses alunos garantindo o seu ingresso, bem como a sua permanência ao longo da jornada estudantil, em igualdade de condições com os demais. É necessário que o Poder Público promova ações no sentido de oferecer instrumentos que garantam o pleno exercício dos direitos e uma oportunidade de vida humana digna.

Por fim, deve-se compreender que lei a 13.146/2015 que concebe o Estatuto da Pessoa com Deficiência traz um desafio à sociedade, que é a necessidade da mudança de paradigmas, pois estabelece que a deficiência é resultante da condição do indivíduo e da sua interação com o meio, ou seja, com as barreiras que lhe são impostas e impedem o pleno exercício dos seus direitos. Deste modo, é importante que a lei seja concretizada em todos os seus termos e materializando os seus direitos, para que assim a pessoa com deficiência possa participar ativamente das relações sociais, em exercício pleno da dignidade humana.

Página 37 Caderno de Ciências Sociais Aplicadas, Vitória da Conquista/BA, vol. 15, n 25, ano 15, p. 19-39, jan/jun 2018. 


\section{Referências}

BRASIL, República Federativa do. Constituição da República Federativa do Brasil. Brasília: Senado Federal, 1988.

BRASIL. Lei 13.146 de 2015. Disponível em: <http://www.planalto.gov.br/ccivil_03/_Ato20152018/2015/Lei/L13146.htm>. Acesso em 09 de setembro de 2016.

BRASIL. Secretaria de Educação Fundamental. Parâmetros curriculares nacionais : Adaptações Curriculares / Secretaria de Educação Fundamental. Secretaria de Educação Especial. - Brasília : MEC / SEF/SEESP, 1998. Disponível em: <http://www.conteudoescola.com.br/pcn-esp.pdf> . Acesso em 06 de setembro de 2016.

BULOS, UadiLammêgo. Curso de Direito Constitucional. 3 ed. Saraiva: São Paulo, 2009, p. 420.

CAMBI, Eduardo; ZANINELLI, Giovana. Direito fundamental à educação, exclusão social e cidadania. In: Doutrinas essenciais de Direito Constitucional. Vol. 9/2015, p. 721-748, ago./2015.

CARVALHO, R.E. Diversidade como paradigma de ação pedagógica na Educação. In: Revista da Educação Especial. MEC/SEESP. Out. 2005

CURY, Carlos Roberto Jamil. DIREITO À EDUCAÇÃO: DIREITO À IGUALDADE, DIREITO À DIFERENÇA. Cadernos de Pesquisa, n. 116, julho/ 2002 Cadernos de Pesquisa, n. 116, p. 245-262, julho/ 2002. Disponível em: <http://www.scielo.br/pdf/cp/n116/14405.pdf>. Acesso em 06 de setembro de 2016.

DWORKIN, Ronald. Levando os direitos a sério. 3. ed. São Paulo: Martins Fontes, 2010.

MENDES, Gilmar Ferreira; BRANCO, Paulo Gustavo. Curso de Direito constitucional. 9. ed. São Paulo: Saraiva, 2014

SALES, Elielson. Deficiência e Educação: uma perspectiva histórica da educação de surdos. Interfaces da Educação (UEMS/Paranaíba/MS), v.3, n.9, p.30-44, 2012. Disponível em: $<$ http://www.porsinal.pt/index.php?ps=artigos\&idt=artc\&cat=7\&idart $=253>$. Acesso em 10 de setembro de 2016.

SARLET, Ingo Wolfgang. Algumas considerações em torno do conteúdo, eficácia e efetividade do direito fundamental à saúde na Constituição de 1988. Revista Eletrônica sobre a Reforma do Estado. N.11, 2007, Salvador.

SARLET, Ingo Wolfang. Dignidade da Pessoa Humana e Direitos Fundamentais na Constituição Federal de 1988. Porto Alegre: Livraria do Advogado, 2009.

SILVA, Otto Marques da.Epopéia Ignorada - A História da Pessoa Deficiente no Mundo de Ontem e de Hoje. 1987.

Página 38 Caderno de Ciências Sociais Aplicadas, Vitória da Conquista/BA, vol. 15, n 25, ano 15, p. 19-39, jan/jun 2018. 
STOLZE, Pablo. Estatuto da Pessoa com Deficiência e sistema de incapacidade civil. Revista Jus Navigandi, Teresina, ano 20, n. 4411, 30 jul. 2015. Disponível em: <https://jus.com.br/artigos/41381>. Acesso em: 4de setembro de 2016.

Supremo Tribunal Federal. Disponível em: <http://www.stf.jus.br/portal/principal/principal.asp>.Acesso em 13 de setembro de 2016.

UNESCO. Declaração de Salamanca e Linha de Ação sobre Necessidades Educativas Especiais. Brasília: CORDE, 1994. 